\title{
Da Polícia Especial até o BOPE e a CORE: as polícias do Rio de Janeiro e o desenvolvimento de suas unidades de elite
}

\author{
Thiago Pacheco ${ }^{1}$
}

\begin{abstract}
RESUMO
Este estudo constitui-se de uma análise das origens institucionais das unidades de elite das polícias do Rio de Janeiro. Com o surgimento dessas unidades, surge também a ideia de distinção e separação de seus agentes com relação ao restante da polícia, tida como inapta ou mesmo corrupta. Argumenta-se aqui que tal ideia demonstra a consciência dos problemas que a polícia tem apresentado, e mascara a interdependência dos segmentos ligados à Segurança Pública gerando a ilusão de que grupos como o BOPE ou a CORE são órgãos independentes ou superiores aos demais, ao contrário de partes integrantes e complementares das instituições policiais às quais pertencem.
\end{abstract}

Palavras-chave: Polícia; Unidades de Elite; Segurança Pública

\begin{abstract}
This study consisted in analyzing the institutional origins of the elite units in the police of Rio de Janeiro. With the creation of these units, there is also the idea of distinction and separation from their agents with respect to the rest of the police, considered inept or even corrupt. It is argued here that such an idea demonstrates awareness of the problems that the police have presented, and masks the interdependence of the segments related to Public Safety generating the illusion that groups like BOPE and CORE are independent bodies or superior to the other, unlike of integral and complementary parts of the law enforcement institutions to which they belong.
\end{abstract}

Keywords: Police; EliteUnits; PublicSafety

1 Doutorando em História pela Universidade Federal do Rio de Janeiro - UFRJ. Pacheco/Pacheco.thiago@ibest.com.br 


\section{Introdução}

Inseridas nas estruturas policiais do Estado do Rio de Janeiro, duas unidades especiais têm se destacado devido a seu treinamento voltado para situações extremas e de alta periculosidade: o Batalhão de Operações Especiais (BOPE) na Polícia Militar e a Coordenadoria de Recursos Especiais (CORE) na Polícia Civil. Os agentes dessas unidades apresentam-se como policiais distintos e altamente capacitados em comparação aos demais, com alto desempenho em confrontos contra criminosos pesadamente armados e em terrenos adversos (como as favelas).

Entretanto, a ideia de uma unidade especial, altamente qualificada e distinta do restante da polícia, é bem anterior à década de 1970, contexto embrionário tanto da CORE quanto do BOPE. Já nos primeiros anos da década de 1930, foi criada uma unidade policial de elite dentro da Polícia Civil carioca voltada para operações de choque, confrontos contra distúrbios políticos, escolta motorizada e combate com metralhadoras. Tratava-se da Polícia Especial, formada por atletas e policiais escolhidos a dedo, pretensamente dignos do respeito da população e da confiança dos governantes.

Nesse sentido, a concepção de uma unidade de polícia de elite não é inédita nem recente na polícia do Rio de Janeiro. De forma semelhante, a ideia de que a polícia é indigna de confiança e, por isso, o agente da polícia de elite diferencia-se pela sua idoneidade e treinamento, está presente e é uma preocupação já nas primeiras décadas do século XX.

Neste trabalho, pretende-se fazer um histórico do desenvolvimento dessas unidades de elite na Polícia Carioca, herdadas pelo Estado do Rio de Janeiro, rastreando este sentimento de um policial que seria diferente por fazer parte desses segmentos. Mais do que uma cultura institucional que distingue os membros dessas unidades, tal ideia demonstra, como será discutido mais adiante, uma consciência dos problemas apresentados pelas estruturas policiais e o equívoco em se desconsiderar que os membros da CORE e do BOPE, a despeito de apresentarem-se como policiais distintos, fazem parte institucionalmente dessas mesmas estruturas. 


\section{A Polícia Especial}

No bojo do processo de centralização política empreendida por Vargas (que culminou no Estado Novo, instaurado em 1937), a Polícia Civil do Distrito Federal passou por uma reestruturação durante a década de 1930 a fim de adaptar-se aos novos tempos (APERJ, 1993). Como parte desse processo de reestruturação, foi concebido um segmento policial elitizado, que fosse marcado não apenas pela excelência de suas habilidades como pela distinção de seus policiais: a chamada Polícia Especial.

A Polícia Especial foi criada entre agosto de 1932 e janeiro de $1933 .^{2}$ Era destinada a operações de choque, conflitos e dispersões de multidões. Num sentido mais amplo, tratava-se de um grupamento de elite destinado a operações que fossem importantes demais para serem deixadas a cargo da "polícia comum". ${ }^{3}$ Nesse sentido, além de pelotões de choque, a Polícia Especial seria composta de agentes treinados no uso de metralhadoras (alto poder de fogo para a época) e de motociclistas que atuariam como batedores e escoltas a autoridades (Reznik, 2008:163).

Os primeiros agentes da Polícia Especial foram compostos por cinquenta membros da Guarda Civil, cinquenta militares e cem atletas selecionados pelos clubes do Rio de Janeiro (Reznik, 2008:163). Oficialmente, tratou-se de uma seleção rigorosa que visava colher os homens mais distintos e na excelência de suas condições físicas para compor o segmento de elite da polícia carioca:

[...] escolhendo elementos, cujos nomes somente fossem um cartaz de propaganda. Estudantes e esportistas, que no Rio são os verdadeiros ídolos do povo, foram os elementos escolhidos para completar a maior parte do efetivo do Polícia Especial. ${ }^{4}$

O treinamento dessa unidade era peculiar para a época. Além da exaustiva prática de esportes, sua formação envolvia a capacitação no uso de armas de fogo, lança-granadas e enfrentamento a multidões, seus agentes também eram submetidos a treinamento de combate corporal como jiujistu, boxe e até mesmo a capoeira:

\footnotetext{
${ }^{2}$ Luís Reznik estipula a data de 5 de agosto de 1932 (2008:163). Entretanto, o relatório policial de 1933 declara a data de criação do órgão em 10 de janeiro de 1933 (Fundo DPS, 866).

${ }^{3}$ Ou seja, da Guarda Civil, que eram agentes da polícia civil uniformizados, responsáveis pelo policiamento ostensivo. Foi extinta em 1969, com as mudanças estruturais empreendidas pela Ditadura Civil-Militar de 1964.

${ }^{4}$ Arquivo Público do Estado do Rio de Janeiro, Fundo DPS, notação 866, p. 2.
} 
A instituição policial em sua seção de "Ataque e Defeza", compreendendo luta-livre, box, capoeiragem e jiu-jitsu, consta do manejo de armamento, casse-tête, tiro ao alvo, de pistola ou rifle, manejo de bomba lacrimogênea, exercícios em conjunto do grupo de choque; de aulas teóricas e assuntos policiais que interessem diretamente a profissão. ${ }^{5}$

Mas não era apenas com o treinamento de seus agentes que a Polícia Especial se preocupava. Esses policiais deveriam ser diferentes dos demais, pois, se agissem como eles, não teriam o respeito da sociedade. O componente desse órgão supostamente destacava-se por esta distinção, que, junto ao treinamento, faziam deles policiais dignos de confiança:

Sendo assim o mais importante do programa de sua organisação, foi crear um ambiente, já não digo de simpatia, porém de confiança, porque se a Polícia Especial iniciasse suas atividades usando dos meios sadorios da polícia preventiva, breve se desmoralisaria e já não teria o respeito moral necessário; se cumprisse integralmente seu papel de repressão, adquiriria o ódio do povo, tornando-se insustentável a situação. ${ }^{6}$

Ou seja, procurou-se constituir, dentro da Polícia Civil, um grupo de agentes eficazes, mais bem treinados e em melhores condições físicas que os demais policiais, capazes de efetuar combates armados e desarmados contra os possíveis oponentes da realidade carioca naquele contexto. Esses agentes também seriam mais confiáveis, na medida em que eram movidos por um sentimento de lealdade, honestidade e decência que lhes seriam peculiares. A Polícia Civil do Rio de Janeiro, desta forma, contaria com um segmento interno especializado, eficaz, confiável e bem treinado para o cumprimento das missões institucionais mais importantes e complexas.

Portanto, a Polícia Especial era parte da Polícia Civil, estando inserida nela como um organismo especializado. Podemos analisar esta inserção a partir do que Max Weber classifica serem associações autônomas ou heterônomas, e autocéfalas ou heterocéfalas (Weber, 2002). Dentro desta concepção, uma associação autônoma determina seu governo internamente, sem interferência externa, sendo o oposto de uma associação heterônoma, na qual o modelo de gerência é determinado por organismos externos. Quanto à ideia de associação autocéfala, a liderança tem total autonomia na gerência da mesma, o que não ocorre nas associações heterocéfalas obrigadas a prestar contas a autoridades externas.

\footnotetext{
${ }^{5}$ Id., p. 11. Mantivemos a ortografia original da época (nota da revisora).

${ }^{6}$ Id., p. 2. Novamente, citação com ortografia da época (nota da revisora).
} 
A partir destas distinções, observa-se que a Polícia Especial tratava-se de associação heterônoma, na medida em que seu comando era definido pela Chefia da Polícia Civil. ${ }^{7}$ De forma semelhante, a Polícia Especial era um organismo heterocéfalo, na medida em que suas operações eram definidas também pela Chefia da Polícia Civil, à qual devia prestar contas.

A criação da Polícia Especial envolveu um discurso de distinção e honra em comparação ao restante da polícia, a despeito de fazer parte dela. Para seu comandante, esta unidade era: "[...] considerada como um corpo de elite, e os mais simples policiais gozam de grande conceito em todas as suas camadas sociais", 8 sendo símbolo de orgulho para estes policiais o quepe vermelho em conjunto com um elegante uniforme cáqui que usavam (Reznik, 2008:163). ${ }^{9}$ A Polícia Especial existiu até 1960, quando o Rio de Janeiro fundiu-se ao antigo Estado da Guanabara. O órgão foi então dissolvido, sendo seus agentes transferidos para o quadro de detetives da Polícia do novo estado.

\section{CORE}

A Polícia Civil do Estado do Rio de Janeiro dispõe de um setor especializado, destinado a operações de alto risco. Trata-se da Coordenadoria de Recursos Especiais CORE - formada por policiais treinados para dar suporte às demais unidades e delegacias da Polícia Civil em situações de alta periculosidade. Vejamos como se formou tal instituição.

O embrião da CORE foi estabelecido durante a Ditadura Civil-Militar, em 1969, quando da criação do GOE (Grupamento de Operações Especiais). Constituía-se de doze policiais treinados para dar apoio a operações da Polícia Civil. O GOE expandiu-se em 1971, quando foi transformado no Serviço de Operações Especiais (SERESP): o número de agentes subiu para 38, alguns deles atiradores de elite, formação inédita entre as polícias brasileiras até aquele momento (Reznik, 2008:207).

Com a fusão do Estado da Guanabara e do Rio, o órgão tornou-se Divisão de Operações Especiais (DOE). Mais tarde, Coordenadoria de Inteligência e Apoio Policial (CINAP) e, por fim, em 2002 passou a ser designado CORE (Reznik, 2008:207). Sua função

\footnotetext{
${ }^{7}$ Cf. Decreto ${ }^{\circ} 24.531$, de 2 de Julho de 1934.

${ }^{8}$ Arquivo Público do Estado do Rio de Janeiro, Fundo DPS, notação 866, p. 8.

${ }^{9}$ Este sentimento é igualmente encontrado no BOPE, por exemplo, orgulhoso de seu uniforme negro e do símbolo da "faca na caveira" (cf. Soares, Batista e Pimentel, 2006).
} 
tem sido basicamente a mesma: um segmento policial especializado e de elite, destinado a operações de resgate, busca, apreensão e prisão em situações de altíssima periculosidade.

Neste sentido, a CORE destina-se a complementar as necessidades estabelecidas pelas demandas da Polícia Civil, da qual faz parte e, num sentido mais amplo, da própria Secretaria de Segurança Pública. Escapa à proposta desta análise esmiuçar os efeitos colaterais e a eficácia dos projetos de combate à criminalidade adotadas pelo Estado do Rio de Janeiro nas últimas décadas, mas é importante salientar que esses mesmos projetos exigem um organismo policial rigorosamente bem treinado, ágil e eficaz para o combate em diferentes tipos de terrenos (muitos deles urbanizados) e contra criminosos que, não raro, estão pesadamente armados.

Exige-se do agente da CORE, portanto, excelente condição física e um árduo treinamento num curso nomeado COTE (Curso de Operações Táticas Especiais). O aspirante a fazer parte desse órgão é submetido a uma intensa formação na qual são ministradas técnicas de combate em ambientes urbanos, luta corporal, paraquedismo, rapel, combate a curta distância e desativação de explosivos, além de refinar sua capacidade de tiro. Os poucos aprovados no curso passam a fazer parte da instituição. ${ }^{10}$

Observa-se que a CORE, assim como a Polícia Especial entre as décadas de 1930 e 1950, constitui-se de uma associação heterônoma, na medida em que a direção deste órgão é determinada pelo Chefe de Polícia. ${ }^{11}$ Não se trata de organismo independente, mas de um segmento interno da instituição policial, cujo objetivo é prestar apoio às operações mais arriscadas empreendidas pela Polícia Civil.

De forma semelhante, a CORE não desfruta de total autonomia para sua própria gerência, constituindo-se numa associação heterocéfala. A atuação da CORE é, ao menos oficialmente, determinada e regulada pela chefia da Polícia Civil e em função das demandas desta instituição. Ou seja, a CORE não somente faz parte como é um segmento constituído a partir do que se entende serem as necessidades da polícia investigativa fluminense.

Entretanto, ao contrário da Polícia Especial, cujo efetivo era composto em parte por indivíduos de fora das esferas policiais, a CORE é composta por agentes que institucionalmente fazem parte dos quadros de carreira da Polícia Civil. Não se trata de um

\footnotetext{
${ }^{10} \mathrm{http} / / / \mathrm{ultimosegundo.ig.com} . \mathrm{br} / \mathrm{brasil} / \mathrm{rj} /$ treinamento+duro+para+entrar+na+core+elite+da+policia+civil/n1237 826025308.html, acesso em 11 de agosto de 2013.

${ }^{11}$ Como no caso relatado na seguinte reportagem: http://g1.globo.com/rio-de-janeiro/noticia/2012/03/chefia-dapolicia-civil-no-rio-muda-comando-da-core.html, acesso em 10 de agosto de 2013.
} 
órgão externo, independente nem composto por pessoas estranhas à polícia investigativa. Eles iniciam suas carreiras como policiais civis e, em algum momento de suas carreiras, voluntariam-se a fazer parte da CORE (Reznik, 2008:208), trabalhando neste segmento caso sejam aprovados no curso de formação. Noutras palavras, os membros da CORE são agentes de formação da Polícia Civil e não deixam de fazer parte desta instituição durante toda a sua carreira.

Além do treinamento e das perfeitas condições físicas, há também um discurso de valores morais que são exigidos do agente da CORE. Segundo o delegado Rodrigo Oliveira, estes policiais: "Precisam ter valores como honestidade, prudência, companheirismo e fidelidade à polícia e à sociedade" (apud Reznik, 2008:208). Esses valores relacionados estão com uma espécie de "culto ao policial de operações especiais", expresso pelos próprios componentes do órgão:

Como no Bope, há um culto ao "policial de operações especiais", tido como mais preparado que os demais. Nas paredes de entrada da sede da unidade, ao lado da sede da Chefia de Polícia, no centro, leem-se a "Oração das Forças Especiais" e a lista dos 98 formados pelo Curso de Operações Táticas da Core e pelo Curso de Operações Especiais Policiais (COEsP) e a divisa "Falcão Sempre!". ${ }^{2}$

Ou seja, à semelhança da Polícia Especial, o agente da CORE apresenta-se como um agente distinto se comparado aos demais colegas policiais. Esta mesma expressão de diferenciação é encontrada no Batalhão de Operações Especiais (BOPE) da Polícia Militar, como veremos a seguir.

\section{BOPE}

O BOPE constitui-se na tropa de elite da Polícia Militar do Estado do Rio de Janeiro, sendo composta por policiais extremamente bem treinados e destinados às operações complexas em áreas e situações de alta periculosidade. Segundo o sítio eletrônico do Batalhão de Operações Especiais, temos a seguinte definição: ${ }^{13}$

\footnotetext{
${ }^{12} \mathrm{http} / / /$ ultimosegundo.ig.com.br/brasil/rj/tropa+de+elite+core+faz+de+invasao+tatica+a+retrato+falado/n12378 25977107.html, acesso em 10 de agosto de 2013.

${ }^{13}$ Disponível em http://www.bopeoficial.com/o-batalhao/batalhao, acesso em 3 de fevereiro de 2013.
} 
O Batalhão de Operações Policiais Especiais (BOPE) é uma força de intervenção da Polícia Militar do Estado do Rio de Janeiro (PMERJ), responsável por atuar em situações críticas, sendo a reserva tática de pronto emprego da Corporação. Seu efetivo é voluntário, formado por policiais de elevado preparo técnico, tático e psicológico.

A atribuição operacional (resgate e confronto de alto risco) e a inserção orgânica do grupo de operações especiais dentro da Polícia Militar são características deste grupo desde sua formação no fim dos anos 1970. Um histórico da formação do BOPE demonstra não apenas de forma mais clara esta inserção, mas também a gênese e o desenvolvimento policial militar desta unidade.

Em 19 de janeiro de 1978 foi criado o Núcleo da Companhia de Operações Especiais (NuCOE). Seus policiais eram voluntários alegadamente "dotados de comprovada integridade moral", alguns deles com especialização nas Forças Armadas. Em 1982, o núcleo mudou sua designação para Companhia de Operações Especiais (COE), funcionando nas instalações do Batalhão de Polícia de Choque (BPChq). Após seis anos, o COE transformou-se na Companhia Independente de Operações Especiais, configuração que se manteve até $1^{\circ}$ de março de 1991, quando tornou-se Batalhão de Operações Policiais Especiais (BOPE). ${ }^{14}$

Nota-se, na sequência que acaba de ser demonstrada, que o BOPE é criado e desenvolvido dentro da PMERJ e voltado para as demandas elencadas por esta corporação. Configura-se, portanto, como uma associação heterônoma, na medida em que o comandante do Batalhão de Operações Especiais é escolhido pelo Estado Maior da Polícia Militar do Estado do Rio de Janeiro e pelo secretário de Segurança Pública. O lugar institucional do BOPE é determinado pelo comando da corporação e pelo governo do estado, constituindo-o como um aparato sofisticado que dota a polícia de potencial para atuação em situações extremas de combate, resgate e salvamento.

Da mesma forma, a gerência do Batalhão de Operações Especiais não é totalmente autônoma, tendo de prestar contas ao Estado Maior da Polícia Militar do Estado do Rio de Janeiro, que também determina sua atuação (por definição, operações de caráter especial). Assim como a Polícia Especial nas décadas passadas e a CORE atualmente, o BOPE opera de forma legítima somente conforme deliberação do alto escalão da instituição da qual faz parte.

Também a exemplo do que ocorre na CORE, o componente do BOPE é, antes de tudo, membro da corporação. Trata-se de um policial militar de formação, enquadrado nos quadros

\footnotetext{
${ }^{14}$ http://www.bopeoficial.com/o-batalhao/historico, acesso em 3 de fevereiro de 2013.
} 
de carreira da PMERJ, treinado e disciplinado de acordo. Somente depois desta formação e subsequente inserção corporativa, este policial poderá ingressar no curso do BOPE, no qual será submetido ao seguinte treinamento: ${ }^{15}$

[...] execução intensiva de sessões práticas e teóricas que proporcionem um perfeito conhecimento e um acentuado adestramento para o cumprimento de missões especiais atribuídas ao BOPE. O curso inclui toda grade curricular do CAT, ${ }^{16}$ além de outras instruções específicas, como mergulho autônomo, vida na selva, montanhismo, paraquedismo, explosivos, combate policial em áreas de alto risco e outras.

O militar do BOPE é, portanto, um policial militar duramente treinado em técnicas de sobrevivência e combate tanto armado como desarmado, além de habilidades para atuar em áreas de alta periculosidade. Trata-se de uma especialização do ofício policial, voltado para as necessidades da Polícia Militar enquanto instituição repressora e responsável pelo policiamento ostensivo e comunitário.

Aqui reside a distinção: o membro do BOPE não se vê nem é visto como policial militar, porque foi separado dos demais através de um treinamento que o tornou diferente. Há uma fronteira entre ele e os demais policiais, que se dá pelo que a tropa de elite não seria: os demais componentes da Polícia Militar são inaptos; o BOPE é o "melhor no que faz"; o restante dos policiais é corrupto; o membro da tropa de elite é incorruptível (Batista, Pimentel e Soares, 2006).

Nesse sentido, mesmo que se aponte o fato de que os componentes do BOPE sejam institucionalmente policiais militares, ainda assim persiste um processo simbólico de diferenciação que extrapola este campo corporativo. O que torna os membros do Batalhão de Operações Especiais distintos tanto para si quanto para os demais policiais como até mesmo para a sociedade é a construção e estabelecimento de uma identidade enquanto parte de um grupo elitizado, eficaz, poderoso e incorruptível.

\footnotetext{
15 www.boperj.org, Curso de Operações Especiais.

${ }^{16}$ O CAT é uma versão condensada do mesmo curso, também oferecido pelo BOPE, no qual o policial militar recebe instrução tática individual, operações em altura, socorros de urgência, combate corpo a corpo, técnicas especiais de tiro, táticas especiais, técnicas especiais de patrulha entre outras. http://www.bopeoficial.com/cursos/cat/acesso em 3 de fevereiro de 2013.
} 


\section{A consciência de distinção dentre as unidades especializadas}

A concepção de um segmento interno especializado e elitizado, portanto, fez parte do aparato policial carioca durante boa parte do século XX. Com a criação da Polícia Especial em 1932, excetuando-se o aparente hiato de nove anos entre 1960 (quando o órgão foi extinto) e 1969 (criação do GOE, embrião da atual CORE), esta concepção pode ser percebida atualmente na estrutura de segurança pública do Estado, na qual tanto a CORE como o BOPE constituem-se como instrumentos fundamentais.

Observa-se que em todos os casos o segmento de polícia de elite não visa somente a complementar os quadros policiais. Aliás, é justamente o contrário. Tanto a Polícia Especial quanto os demais organismos policiais de elite partem de um discurso interno de que são melhores e mais confiáveis que o restante da polícia, composta pelos inaptos e pelos corruptos.

Ou seja, o árduo treinamento, a seleção rigorosa, a locação institucional distinta e a altíssima qualificação para o combate formaram nestas instituições a construção de uma identidade distinta, que, segundo Kathryn Woodward (2007), pauta-se pela diferença: os agentes especiais destas unidades estabelecem uma identidade própria, exclusiva e independente do restante da polícia, permeada por símbolos e valores que os tornam o oposto do que seria o restante da polícia. A Polícia Especial foi concebida especificamente desta forma, enquanto o BOPE e a CORE foram desenvolvendo esta cultura institucional no decorrer de suas formações.

Nesse sentido, se estabelece um discurso, popularizado após o sucesso dos filmes Tropa de Elite e Tropa de Elite 2, nos quais o agente especial é digno deste nome não somente pela sua especialização para operações de alto risco, mas devido ao fato de que ele é o único policial no qual se poderia confiar. Enquanto o restante da polícia é fraco, inoperante e corrupto, os componentes destes órgãos são honestos, capazes e inabaláveis no combate ao crime (Batista, Pimentel e Soares, 2006:5). Há, portanto, duas polícias: uma boa (honesta, invencível) e outra ruim (desonesta, inútil).

Este é um dado relevante. Atualmente, os métodos policiais e a própria polícia como um todo são alvos de críticas, não gozando estas instituições da confiança da sociedade. Observando-se a constituição da Polícia Especial, percebe-se que tal desconfiança e insatisfação por parte da sociedade com relação à polícia já se fazia presente nas primeiras 
décadas do século XX: considerou-se que, para ser eficaz e respeitável, o novo segmento policial deveria ser diferente da polícia que já existia. ${ }^{17}$

Logicamente, há dessemelhanças entre estas instituições que não podem ser desprezadas. A Polícia Especial foi constituída dentro de um caráter claramente político, visando ampliar os poderes de um Estado em vias de centralização: o crime político, na forma da sublevação, revolta ou golpe ${ }^{18}$ era o temor, não havendo naquele contexto uma criminalidade que exigisse grupos militares motorizados e armados com metralhadoras.

Situação bem diferente enfrenta a Polícia Militar nos dias de hoje e desde a abertura política ocorrida nos anos 1980. Responsável pelo policiamento ostensivo e comunitário, o BOPE (tanto culturalmente como operacionalmente) é uma resposta ao contexto de guerrilha urbana contra traficantes pesadamente armados. ${ }^{19}$ De forma semelhante, sem um segmento orgânico altamente bem treinado para operações especiais, atividades da Polícia Civil, como busca, apreensão e prisão, seriam simplesmente impossíveis em certas áreas e situações de alta periculosidade.

Entretanto, para além destas particularidades, a ideia de que existe mais de uma polícia, separadas por polarizações como capaz/incapaz ou honesta/corrupta, demonstra historicamente um certo descaso e uma ilusão de ótica na formação das estruturas policiais do Rio de Janeiro.

Descaso porque, diante do reconhecimento dos problemas que a polícia tem apresentado, tem-se optado por uma solução simplista e nociva. Isto fica demonstrado já na década de 1930: a Polícia Especial é criada partindo-se do princípio que o aparato policial existente não funcionava a contento. De forma semelhante, alimentar ou concordar com a ideia de que os agentes do BOPE e/ou da CORE são os combatentes do crime que o restante dos policiais não consegue ou não quer ser é acomodar-se diante dos problemas reais que têm impedido a polícia de cumprir sua missão institucional de proteger o cidadão.

Ilusão de ótica porque as polícias são organismos interdependentes, tanto internamente quanto externamente. Já foi demonstrado o caráter heterônomo e heterocéfalo destes

\footnotetext{
${ }^{17}$ Inclusive, já no começo do século se dizia que a polícia abusava de seu poder e não era bem preparada. A própria Guarda Civil teria sido concebida, em 1904, para superar tais problemas. Apesar de ser elogiada, esta Guarda Civil foi perdendo seu prestígio no passar dos anos (cf. Reznik, 2008:121-123).

${ }^{18}$ O relatório policial de 1933 deixa claro esse caráter repressor da Polícia Especial: “[...] nasceu pela necessidades natural das grandes cidades, com o fim de coibir, por meios enérgicos, as manifestações do povo contra o Governo e a ordem pública, em épocas anormais" (Arquivo Público do Estado do Rio de Janeiro, Fundo DPS, notação 866, p. 1).

${ }^{19}$ Não se quer aqui justificar ou defender tal política de enfrentamento. A análise restringe-se às causas e consequências destas estruturas policiais.
} 
segmentos policiais: ou seja, eles fazem parte da polícia (Civil ou Militar) e não estão, de forma alguma, fora da estrutura institucional dela. Existem somente devido a demandas e necessidades policiais. Não se trata de "outra polícia", mas de organismos internos produzidos pela e para a mesma polícia tida como ineficaz e corrupta.

Mas esta questão torna-se mais delicada ainda quando rastreamos as origens destes policiais. Metade dos primeiros agentes da extinta Polícia Especial era composta por homens de fora da polícia, e posteriormente seus quadros foram acessados diretamente por concurso público (Reznik, 2008:163), o que fazia dela um grupo social quase que totalmente distinto do restante da polícia (ainda que participante dela). O mesmo não se pode afirmar do BOPE e da CORE, cujos membros são, respectivamente, policiais militares e civis de formação que em algum momento foram alocados para estas unidades. Todos eles tiveram uma carreira fora dos segmentos de elite, tratando-se de agentes especializados da polícia, e não "de outra polícia". ${ }^{20}$

Além disso, a polícia não é um instrumento isolado de segurança e justiça. No atual contexto democrático, ela está inserida num conjunto de leis e de prestação de contas à sociedade, a qual deve proteger. No caso da Polícia Civil, é ligada ao sistema judicial para o qual encaminha o resultado de suas investigações (Kant de Lima, 2008). Nesse sentido, estabelecer unidades de combate voltadas para operações de emergências e de alta periculosidade como a "polícia que funciona" é ignorar o policiamento ostensivo que garante a ordem cotidianamente e, mais grave ainda, o policiamento inteligente e investigativo que esclarece os crimes. Na prática, o que se tem visto não é outra polícia mais "honesta" e "preparada", mas sim um organismo mais violento e preparado para combate. A não ser que se reduza o papel da polícia ao de ser um instrumento de enfrentamento e eliminação de inimigos, o que não tem sido eficaz, as unidades de elite precisam ser segmentos auxiliares nas estratégias de policiamento, ao contrário dos carros chefes destas mesmas estratégias.

Além disso, o restante da polícia prossegue apresentando seus problemas crônicos, somados aos da "nova polícia" pautada pela ideia de enfrentamento rápido, eficaz e letal: noutras palavras, a ideia de eliminação de inimigos. Os abusos de poder, a lógica de desconfiança para com certos grupos sociais e os baixos índices de esclarecimentos de crimes são, desta forma, acentuados, e mantêm-se como desafios a serem vencidos para a formação

\footnotetext{
${ }^{20}$ Obviamente, tanto o BOPE como a CORE nutrem uma cultura institucional que lhes é peculiar, exclusiva e excludente. Todavia, este fato não muda suas origens, nem a condição de submissão e inserção de ambas as unidades à Polícia Militar e Civil.
} 
de uma polícia que atenda à demanda de combater a criminalidade e proteger a sociedade de forma não excludente.

\section{Conclusão}

A ideia de um corpo de elite na polícia do Rio de Janeiro não é recente. É bem verdade que a Polícia Especial foi concebida com fins de repressão política mais do que de controle de criminalidade, porém é igualmente perceptível, já na década de 1930, uma insatisfação com os métodos e resultados da polícia "comum", razão pela qual a Polícia Especial procurou se diferenciar e distinguir do modelo vigente (ainda que parte integrante deste).

Atualmente, a constituição de organismos especializados para operações mais perigosas, delicadas e complexas é uma necessidade clara. Não apenas o BOPE, mas também unidades como o Choque e o Canil são unidades fundamentais para que a Polícia Militar cumpra suas missões com sucesso. Da mesma forma, a CORE presta o apoio fundamental do qual a Polícia Civil não pode prescindir. Noutras palavras, as unidades de elite das polícias do Rio de Janeiro têm um papel fundamental para a segurança pública. A questão que urge é uma ampla mudança na cultura e treinamento da polícia como um todo e, no bojo dessas transformações, a redefinição do papel dos policiais de elite dentro desta estrutura.

\section{Referências Bibliográficas}

APERJ - ARQUIVO PÚBLICO DO ESTADO DO RIO DE JANEIRO. DOPS: a lógica da desconfiança. Rio de Janeiro, 1993.

Fundo Polícias Políticas. Setor Administração, dossiê 1, pasta 1-g.

Fundo DPS, notação 866.

BATISTA, André; PIMENTEL, Rodrigo; SOARES, Luiz Eduardo. A Elite da Tropa. Rio de Janeiro: Editora Objetiva, 2006.

BRASIL. Decreto $n^{\circ} 24.531$, de 2 de Julho de 1934. 
G1. Chefia da Polícia Civil, no Rio, muda comando da CORE. O Globo. Rio de Janeiro, 12 mar. 2012. Disponível em <http://g1.globo.com/rio-de-janeiro/noticia/2012/03/chefiada-policia-civil-no-rio-muda-comando-da-core.html>. Acesso em: 11/08/2013.

GOMIDE, Raphael. Tropa de Elite, CORE faz desde invasão tática até retrato falado. Último Segundo. Rio de Janeiro, 13 jan. 2010. Disponível em: <http://ultimosegundo.ig.com.br/brasil/rj/tropa+de+elite+core+faz+de+invasao+tatica+a +retrato+falado/n1237825977107.html>. Acesso em: 11/08/2013.

. Treinamento duro para entrar na CORE, elite da Polícia Civil. Último Segundo. Rio de Janeiro, 13 nov. 2010. Disponível em: <http://ultimosegundo.ig.com.br/brasil/rj/treinamento+duro+para+entrar+na+core+elite +da+policia+civil/n1237826025308.html>. Acesso em: 11/08/2013.

KANT DE LIMA, Roberto. Polícia, Justiça e Sociedade no Brasil: Uma abordagem comparativa dos modelos de administração de conflitos no espaço público. In: KANT DE LIMA, Roberto e MISSE, Michel. Ensaios de Antropologia e de Direito: Acesso à Justiça e processos institucionais de administração de conflitos e produção da verdade jurídica em uma perspectiva comparada. Rio de Janeiro: Edutora Lumen Juris, 2008. pp. 160-199.

POLICIA MILITAR DO ESTADO DO RIO DE JANEIRO. Batalhão de Operações Especiais. Disponível em: < http://www.bopeoficial.com>. Acesso em: 11/08/2013.

REZNIK, Luís. 200 Anos da Polícia Civil do Estado do Rio de Janeiro. Rio de Janeiro: Deorama, 2008.

WEBER, Max. Conceitos Básicos de Sociologia. Rio de Janeiro: Centauro, 2002.

WOODWARD, Kathryn. Identidade e diferença: uma introdução teórica e conceitual. In: SILVA, Tomaz T. (org).; HALL, Stuart; WOODWARD, Kathryn. Identidade $e$ Diferença. A perspectiva dos estudos culturais. Trad. e org.: Thomaz Tadeu da Silva. Petrópolis: Vozes, 2000. 